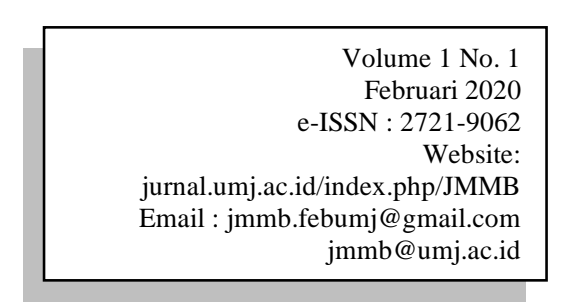

\title{
MENGEMBANGKAN STRATEGI PEMASARAN YANG SUKSES UNTUK CLICK CAFE
}

\author{
Evi Sofia $^{1^{*}}$ dan Agung Wicaksono ${ }^{2}$ \\ ${ }^{1}$ Jurusan Manajemen Bisnis, Fakultas Ekonomi, SBM ITB, Jl.H.R. Rasuna Said, Kuningan, Jakarta, \\ 12950 \\ evi.sofia@sbm-itb.ac.id
}

Diterima: 5 Februari 2020

Direvisi: 10 Februari 2020

Disetujui: 13 Februari 2020

DOI : $10.24853 / \mathrm{jmmb} \cdot 1 \cdot 1.57-66$

\section{ABSTRAK}

Strategi pemasaran efektif sangat penting untuk bisnis apapun tanpa melihat seberapa besar atau kecil ukuran suatu bisnis, dan pemilik bisnis Click Café telah menyadari hal ini. Click Café; sebuah kedai kopi baru yang berlokasi di Ruko Sentra Menteng Bintaro Sektor 7 yang telah beroperasi lebih dari setahun lalu, dan ini merupakan waktu yang tepat bagi Click Café untuk mengevaluasi bisnis kedai kopi tersebut berdasarkan kinerja tahun pertama mereka. Dalam upaya mengembangkan strategi pemasaran yang berhasil untuk Click Café, sangat penting bagi mereka untuk meninjau kembali dan menganalisis situasi bisnis saat ini atau praktik bisnisnya. Situasi bisnis saat ini dipengaruhi oleh beberapa faktor internal dan eksternal. Metode-metode untuk menganalisis situasi seperti STP (Segmenting, Targeting, and Positioning), Marketing Model, dan 4Ps - Marketing Mix Model dipertimbangkan sebagai analisis faktor internal untuk menilai situasi sebuah bisnis (Sumber: Dr. West., Market Analysis and Strategy; Fisher College of Business, OSU; 2014). Di lain hal, faktor eksternal didefinisikan sebagai berbagai macam faktor-faktor di luar sebuah perusahaan yang dapat berdampak atau mampu memengaruhi secara kuat bisnis tersebut. Faktor ini sangat sulit untuk dikendalikan. Seperti banyak orang yang berpendapat bahwa kita tidak memiliki kendali terlalu banyak terhadap faktor eksternal tersebut. Analisis PESTEL dan analisis kompetitor - Porter's Five Forces Model merupakan kategori analisis faktor-faktor eksternal. (Sumber: Dr. West., Market Analysis and Strategy; Fisher College of Business, OSU; 2014).Tujuan dari jurnal proyek akhir ini adalah untuk meneliti dan mengembangkan strategi pemasaran terbaik Click Café untuk dua hingga tiga tahun selanjutnya dengan menggunakan data dari riset pasar yang telah dilakukan.

Kata Kunci: Strategi Marketing, Analisisn SWOT, Click Café. 


\begin{abstract}
The effective marketing strategies are very important to any businesses regardless of the size, and Click Café business owner has realized this. Click Café; the brand new small café located on Ruko Sentra Menteng Bintaro Sector 7 has been operated over a year ago, and it is the right time for them to evaluate this coffee shop's business to find out regarding their first year's performance.
\end{abstract}

This model is very popular and mostly used by market practitioners globally, since it can provide the details in order to be able to construct the current market segments, target market and product positioning. It is for review and analysis purposes for Click Café's future improvement, which is one of many reasons why this model is used to be able to develop the successful marketing strategies for this coffee shop.

In order to develop these, it is important to analyze the current business situation internally and externally using SWOT (Strengths, Weaknesses, Opportunities and Threats) Method.

The internal business situation for Click Café will be observed by its strengths and weaknesses while the external business situation will be based on the opportunities that Click Cafe has and the threats that they are facing. Thru SWOT, any business owner can analyze which items should be reduced and which actions should be completed in order to improve the performance.

The objective of this final project is to research and develop their best successful marketing strategies for next two until three years using the data from the market research that have been completed.

Keywords: Marketing Strategy, STP (Segmentation, Targeting and Positioning) Marketing Strategy Model, SWOT (Strengths, Weaknesses, Opportunities and Threats) Analysis, Click Café. 


\section{PENDAHULUAN}

Click Café telah beroperasi lebih dari setahun lalu, sekitar akhir April 2015. Misi dari Click Café sendiri adalah untuk menyediakan berbagai macam minuman kopi, menu pilihan makanan Indonesia dan Barat, produk kue kering, dan makanan ringan lokal atau appetizers dengan harga terjangkau untuk memenuhi permintaan pasar dimana mayoritas dari mereka adalah mahasiswa dan pekerja sekitar area,dan juga beberapa penduduk berpendapatan menengah yang antusias dengan kedai kopi bertemakan fotografi. Click Café didesain tidak hanya untuk tempat bercengkrama dengan teman atau keluarga saja, namun juga sebagai tempat pertemuan rutin bagi komunitas fotografi. Faktanya, kedai kopi ini juga dapat dijangkau luas oleh berbagai komunitas lainnya, termasuk Old VW Classic Cars Community.

Setelah lima bulan persiapan, pada April 2015 mereka telah membuka kedai kopi kecil di salah satu komplek Small Office Home office (SOHO) di Ruko Sentra Menteng Bintaro Sektor 7. Mereka menamakan bisnis kecil ini dengan "Click Café" untuk mempresentasikan kedai kopi dengan tema fotografi. Mereka merasa nama kedai kopi mereka merupakan nama yang menjanjikan dan mampu membawa tema fotografi tersebut sebagai kesan yang ingin ditonjolkan terhadap Click Café. Mereka telah mendesain logo kedai kopinya seperti di bawah ini - dengan kopi, lensa, gambar kamera, dan tulisan "Click Café" di dalamnya.
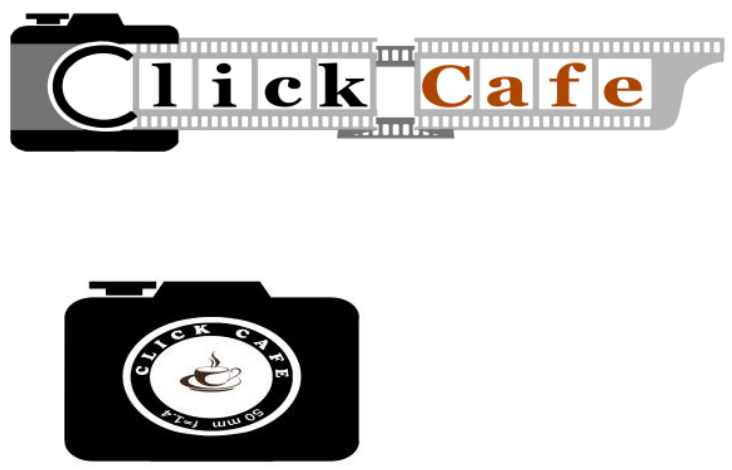

Figure 1. Click Café Logo

Di bawah ini merupakan kondisi keuangan Click Café pada tahun pertama beroperasi (Pendapatan penjualan dan laba/rugi bersih per bulan).

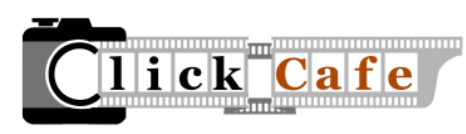

Table 1. Click Café - 1st Year Sales Revenue \& Net Profit / Loss Monthly

\begin{tabular}{|c|c|c|c|c|c|c|}
\hline Oct & Nov & Dec & Jan & Feb & Mar & Apr \\
\hline 25.7 & 19.5 & 25.32 & 21.8 & 24.2 & 27.71 & 27.3 \\
\hline 4.2 & -3.27 & 2.75 & 7.1 & 5.3 & 4.3 & 7.05 \\
\hline \multicolumn{2}{|c|}{$\begin{array}{l}\text { 1st Year } \\
\text { (May '15-Apr '16) }\end{array}$} & May & June & July & Aug & Sept \\
\hline \multicolumn{2}{|c|}{$\begin{array}{l}\text { Sales Revenue } \\
(\mathrm{Rp} \text { in } \mathrm{K})\end{array}$} & 16.57 & 15.23 & 17.57 & 18.58 & 15 \\
\hline \multicolumn{2}{|c|}{$\begin{array}{l}\text { Net Profit / Loss } \\
(\mathrm{Rp} \text { in K) }\end{array}$} & -7.4 & -5.8 & -3.7 & -2.3 & 3.57 \\
\hline
\end{tabular}

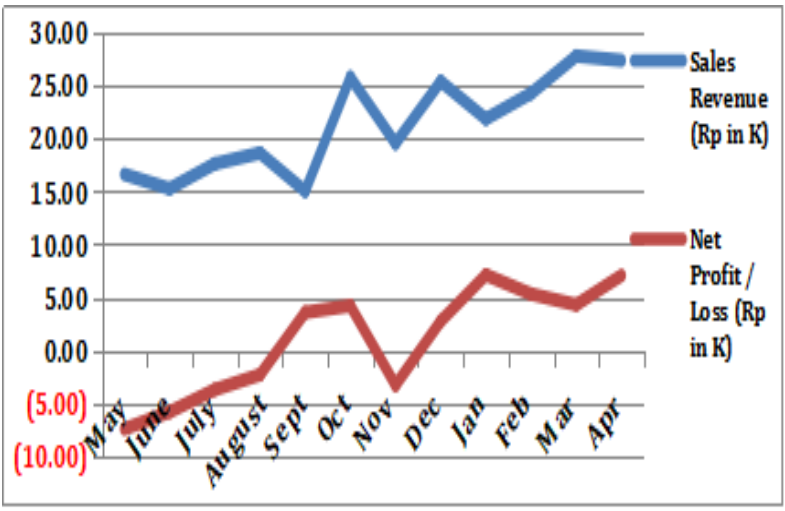

Berdasarkan data di atas dan situasi terkini; terdapat beberapa masalah yang sedang mereka hadapi. Satu diantaranya ialah lokasi Click Café yang kurang berada di area yang ramai, melaikan di dalam komplek SOHO Bintaro. Oleh karena itu, mereka perlu bekerja lebih keras untuk mengenalkan kedai ini kepada masyarakat secara repetitif, dan melakukan strategi rekomendasi mulut ke mulut (word-ofmouth) kepada calon konsumen.

Ini sangat penting untuk menghadirkan kualitas produk terbaik dengan melakukan pelayan yang baik kepada konsumen. Faktor utama lainnya adalah harga yang harus kompetitif di area tersebut, mengingat kedai kopi ini tidak berlokasi di daerah pusat bisnis ataupun area 
sekitar Jakarta, dimana masyarakat memiliki ekspektasi harga yang lebih murah dibandingkan di Jakarta.

\section{Identifikasi Masalah}

Berdasarkan pada data keuangan di atas, penulis telah mengenali bahwa Click Café memiliki masalah pada pendapatannya dimana akan berdampak pada laba bersih mereka. Menurut artikel dari Small Business Chronicle, "the average small coffee shops' total net profit should equal to $7-25 \%$ of their annual sales. Some successful ones can be higher than 25\%". (Sumber:

http://smallbusiness.chron.com/average-profitssmall-cafe-30768.html). Sementara Click Café hanya memiliki laba bersih $4.64 \%$ dari penjualan tahunan selama tahun pertama. Angka ini masih tergolong di bawah rata-rata dibandingkan dengan laba bersih tahunan kedai kopi lain.

Hal ini merupakan masalah utama yang mereka hadapi. Ini disebabkan oleh angka penjualan mereka, sehingga sangat penting bagi Click Café untuk terus bertahan dalam meningkatkan pendapatan. Ini tentu bukan proyek yang mudah, dan ini mengarahkan kita pada pertanyaan penting: Bagaimana cara melakukannya? Bagaimana cara meningkatkan pendapatan Click Café untuk menyentuh dua digit tingkat pertumbuhan dan 10\% hingga $18 \%$ profit margin berturut-turut?

\section{Tujuan Studi, Lingkup, dan Batasan}

Dalam menyelaraskan pertanyaan di atas, studi ini bertujuan untuk:

Mencari tahu pendapat dari para konsumen mengenai produk dan jasa Click Café.

Mengevaluasi situasi Click Café saat ini berdasarkan pendapat konsumen.

Terakhir, menemukan strategi pemasaran yang cocok diterapkan oleh Click Café untuk mengatasi masalah yang mereka sedang hadapi.

Tujuan-tujuan di atas yang dilakukan pada studi ini difokuskan pada Click Café Bintaro untuk meneliti dan mengembangkan strategi pemasaran yang berhasil untuk dua hingga 3 tahun mendatang.

\section{METODE PENELITIAN}

Eksplorasi Masalah Bisnis

Tujuan utama dari riset ini adalah untuk menemukan solusi terhadap masalah bisnis di Click Café, yaitu meningkatkan pendapatan mereka. Untuk membuat studi ini lebih terstruktur dalam mengorganisir ide-ide, penulis menggunakan kerangka konseptual sebagai alat analisis untuk mendukung prosesnya. Kerangka konseptual pertama kali dikenalkan oleh Isiah Berlin pada 1953 melalui esainya "The Hedgehog and the Fox: An Essay on Tolstoy's View of History".

Pada kasus ini, kami telah memulai proses dengan meninjau kembali dan menganalisis faktor-faktor internal mereka dengan menggunakan STP (Segmentation, Targeting, and Positioning) dan Marketing Mix, serta faktor-faktor eksternal dengan menggunakan PESTEL dan analisis kompetitor - Porter's 5 Forces Model. Metode-metode ini digunakan untuk mengevaluasi bagaimana situasi dan kondisi bisnis Click Café saat ini untuk mendefinisikan SWOT (Strengths, Weaknesses, Opportunities and Threats) mereka dengan mengidentifikasikan manakah faktor positif dan negatif pada Click Café. (Sumber: https://en.wikipedia.org/wiki/SWOT_analysis). Ini merupakan bagian awal dari kerangka, dan telah menggunakan berbagai data tersedia dari Click Café, literatur mengenai metode-metode pemasaran yang sudah diimplementasikan pada studi ini, dan juga hasil dari riset pasar yang penulis telah lakukan. 


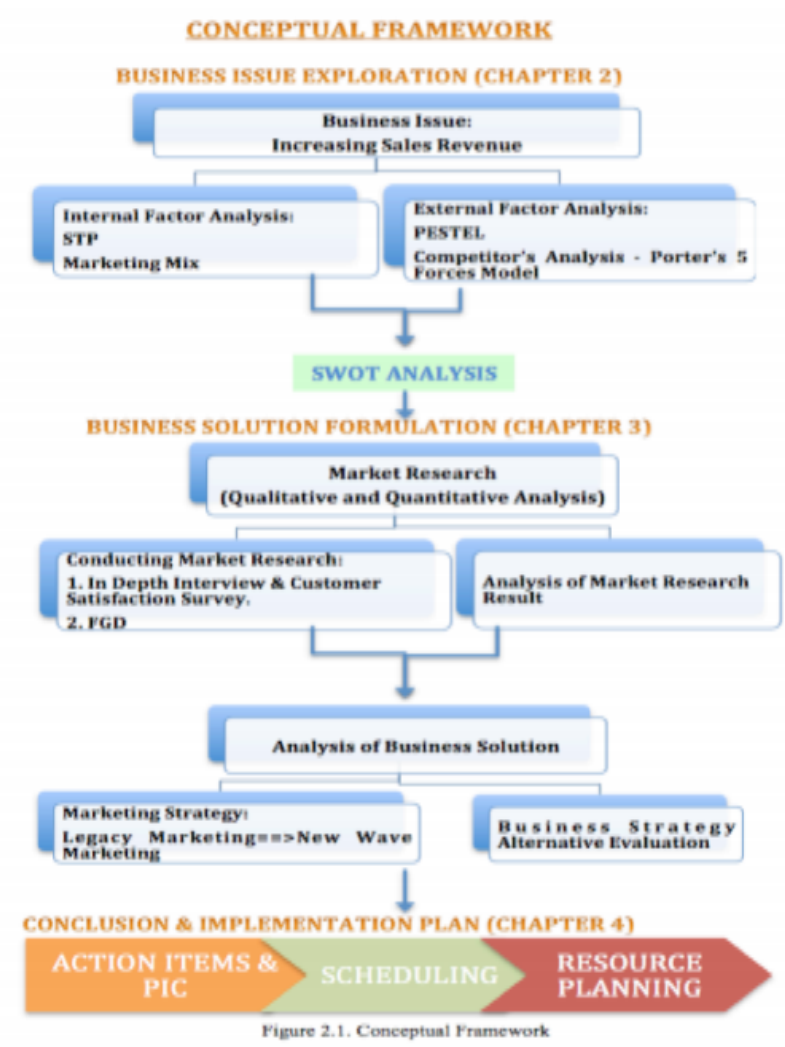

Figure 2. Conceptual Framework

Untuk mengembangkan strategi pemasaran yang berhasil bagi Click Café, sangat penting untuk meninjau dan menganalisis praktik model pemasaran STP (Segmentation, Targeting, and Positioning) saat itu. Pendekatan STP ini akan membantu pemahaman bagaimana melalui segmentasi, target, dan posisi, dapat mendefinisikan pasar yang telah ada dan rencana bagaimana masa depan kita terlihat.

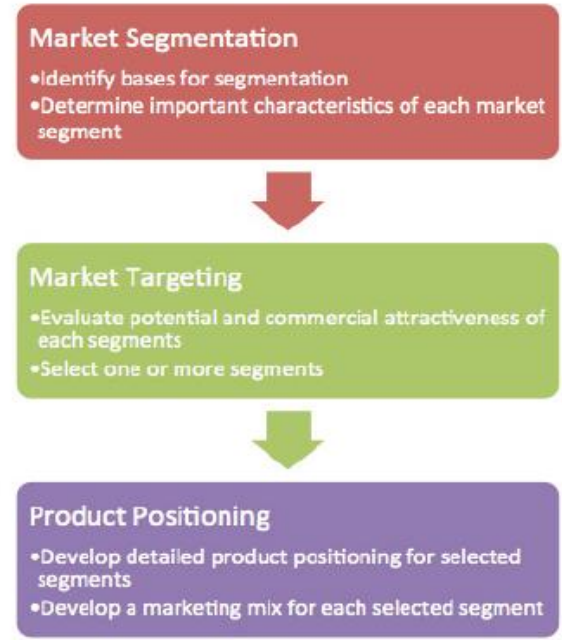

Figure 3. Conceptual Framework Analyzing Current Practice through STP Approach (Source: Hanlon on the Segmentation, Targeting and Positioning Model, 2013)

Dengan menggunakan model ini, terdapat tiga tahapan dalam pengembangan strategi pemasaran yang berhasil. Berikut merupakan tahapan yang berkaitan dengan model pemasaran ini:

1. Melalui segmentasi pasar; tahap ini adalah untuk mengidentifikasi kelompok-kelompok atau konsumen berdasarkan variable segmentasinya; seperti geografi, demografi, sektor industri, umur konsumen, frekuensi pembelian, dll. Ketika telah teridentifikasi, lalu langkah selanjutnya ialah untuk melakukan profil terhadap hasil segmentasi. Informasi ini disediakan oleh riset pasar dan analisis data konsumen. Pada kasus ini, kami menggunakan one-on-one IDI dan Online Customer Survey.

2. Melalui target pasar; tahap ini untuk mengevaluasi dan menganalisis segmen apa yang berpotensi, menarik secara komersial, dan dapat memberikan kontribusi optimal terhadap bisnis. Dengan kata lain, tahapan ini adalah untuk memilih segmen mana yang harus 
difokuskan untuk mendapatkan lebih banyak kontribusi pada bisnis.

3. Melalui posisi produk; tahapan ini untuk mengidentifikasi dan mendeskripsikan bagaimana sebuah bisnis berbeda dari yang lain menurut produk, harga, tempat, dan promosi (4Ps Marketing Mix).
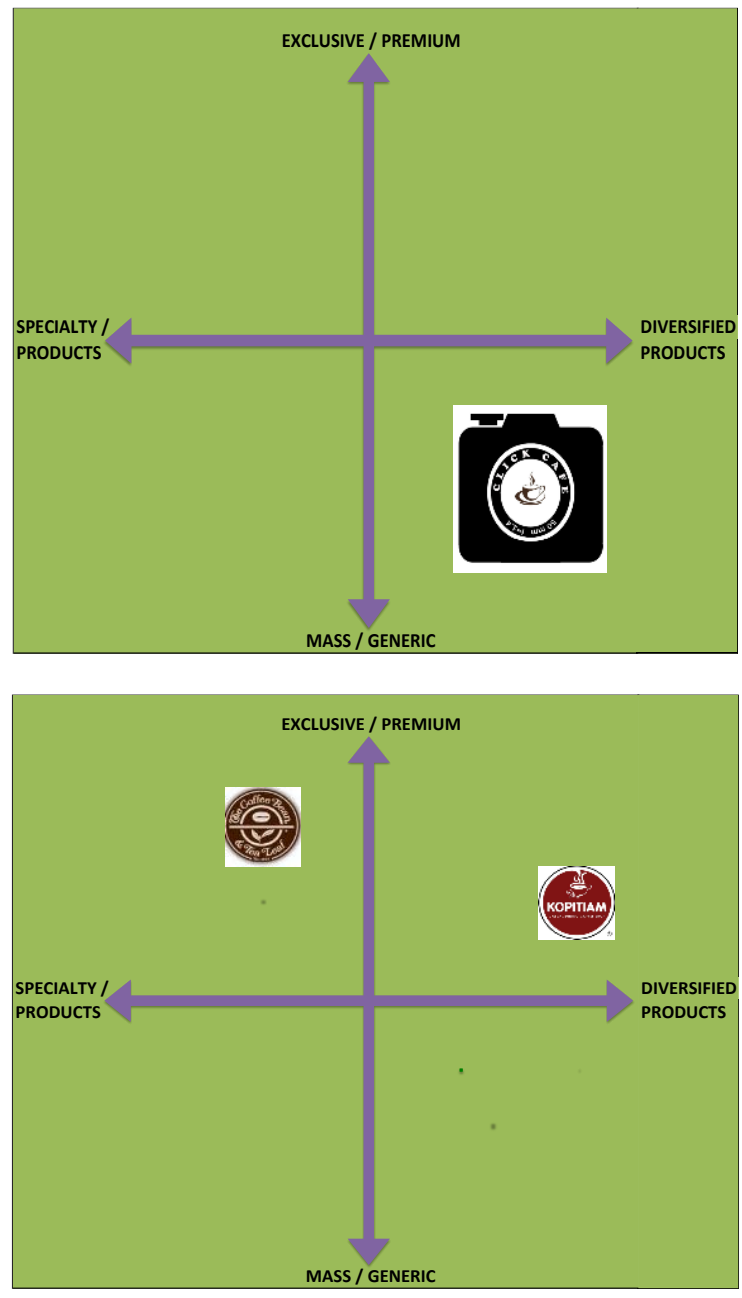

Figure 4. Current Product Positioning - Click Café, KopiTiam and Coffee Beans

Ilustrasi di atas merupakan posisi produk (product positioning) Click Café saat ini dimana termasuk di bawah Mass/Generic dan Diversified Products. The Coffee Bean termasuk di bawah Premium dan Specialty Products category, sementara Kopitiam berada di bawah Premium dan di atas diversified Products category. Sebagai perbandingan dengan Click
Café, bagaimana product positioning dari Kopi Manyar dan Saudagar Kopi? Berikut merupakan proyeksi dari product positioning mereka saat ini.

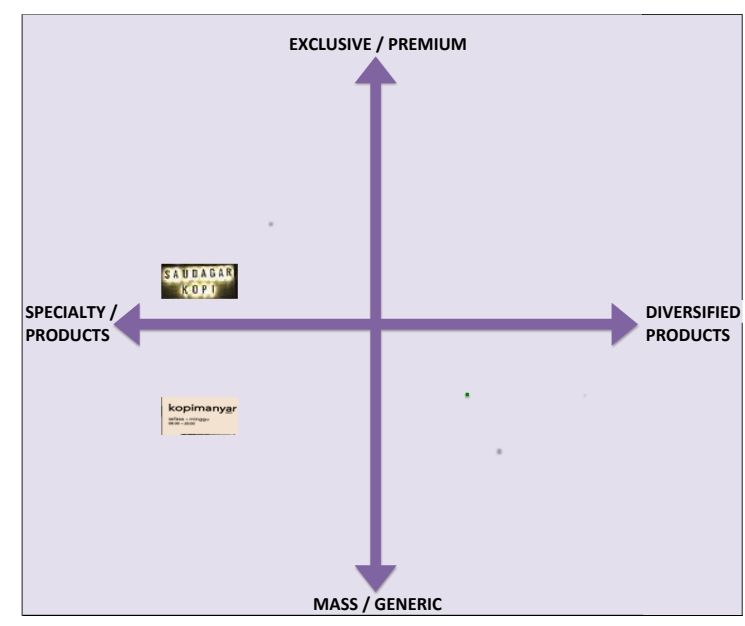

Figure 6. Saudagar Kopi and Kopi Manyar Current Product Positioning

Saudagar Kopi berada di bawah Specialty Products dan sedikit lebih exclusive dari Click Café, sementara Kopi Manyar di bawah Specialty Products dan sedikit Mass/Generic Products Category.

Berada di bawah diversified products positioning, Click Café menawarkan banyak menu mulai dari menu Indonesia hingga menu Barat, berbagai produk kopi hingga produk nonkopi seperti Teh Tarik, Banana Split, Milk Shakes dan lain sebagainya termasuk tipe panas dan dingin. Click Café dipertimbangkan bukan sebagai kedai kopi premium (exclusive) mengingat target pasar mereka. Meskipun mereka dipertimbangkan sebagai Mass/General atau kedai kopi reguler, tetapi mereka selalu memprioritaskan kualitas produknya karena hal tersebut merupakan kunci keberhasilan dari sebuah bisnis kedai kopi. 
Tujuan dari studi ini adalah untuk mengembangkan strategi pemasaran yang berhasil untuk Click Café dalam mencapai objektif ini:

- Peningkatan pendapatan pada volume penjualan mencapai $10 \%$ hingga $18 \%$ profit margin.

- Pengembangan pada brand awareness $\Rightarrow$ untuk mendapatkan konsumen baru dan segmen baru.

- Peningkatan penjualan di tahun yang akan datang $=>$ mencapai dua digit.

- Kesetian dan referensi konsumen.

Dalam mencapai tujuan-tujuan tersebut, sangat penting bagi Click Café untuk menganalisis situasi bisnis internal dan eksternal saat ini menggunakan metodet SWOT (Strengths, Weaknesses, Opportunities and Threats). Alasan yang melatarbelakangi ini adalah mudahnya memahami lingkungan bisnis melalui SWOT untuk memperbaiki situasi bisnis.

Di bawah ini merupakan diagram yang menunjukkan analisis SWOT terhadap situasi bisnis internal dan eksternal Click Café.

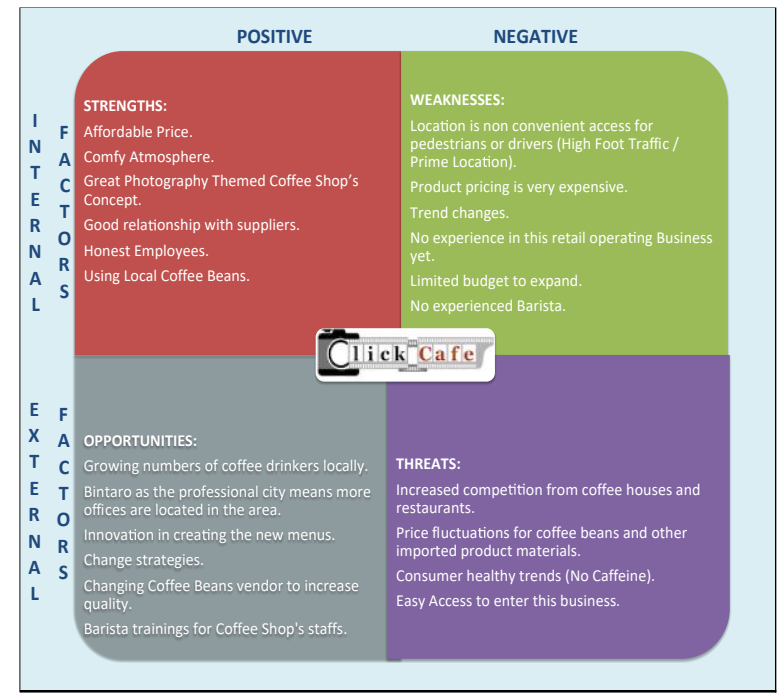

Figure 7. Click Café's SWOT

Analisis SWOT ini menjelaskan detail lengkap situasi bisnis saat ini dan penilaian Kekuatan, Kelemahan, Peluang, dan Ancamannya. Melalui SWOT, setiap pemilik bisnis dapat menganalisis item mana yang harus dikurangi dan tindakan mana yang harus diselesaikan untuk meningkatkan kinerja. Dengan kata lain, pemilik atau praktisi bisnis harus menghilangkan faktor internal negatif atau mengurangi faktor eksternal negatif, dan meningkatkan faktor internal dan eksternal positif. Ini adalah pedoman standar dalam analisis SWOT.

\section{HASIL DAN PEMBAHASAN}

\section{- Solusi Bisnis}

Proses solusi bisnis akan dimulai dengan riset Pasar yang terutama diperlukan untuk menyelesaikan masalah. Riset pemasaran harus didasarkan pada desain penelitian yang dipertanyakan dengan menggunakan riset pemasaran kualitatif dan kuantitatif. Setelah mengumpulkan data dari penelitian atau survei yang disebut proses pengumpulan data, beberapa analisis dan diskusi akan dilakukan untuk mengembangkan teori-teori yang harus diimplementasikan sebagai strategi pemasaran baru yang sukses untuk kedai kopi ini. Ini akan menjadi produk akhir dari penelitian.

Berdasarkan riset pasar di atas, ada item penting yang harus menjadi fokus utama peningkatan Click Café yang akan mengarah pada pencapaian tujuan mereka.Clik Kafe harus fokus pada:

$>$ Kualitas produk.

$>$ Layanan staf Click Café.

$>$ Sangat membina dan melibatkan masyarakat.

> Memperkuat Proposisi Penjualan Unik mereka sebagai Kedai Kopi "Fotografi Bertema".

$>$ Menarik lebih banyak orang secara acak dengan membuat Layout baru di area Click Café.

Berkenaan dengan kualitas produk dan layanan staf Click Café, Click Café harus meningkatkan kualitas produk Click Café, dan meningkatkan layanan staf mereka dengan berkolaborasi dengan ROSSO MICRO ROASTERY untuk 
menjadi vendor dan juga konsultan untuk Click Cafe.

Click Café telah menggunakan Media Sosial lebih sering untuk membina dan terlibat dengan komunitas mereka. Click Café memperlakukan pelanggannya sebagai subjek komunitas, juga dengan "communitizing through listening, talking, energizing, and helping." (Kertajaya, Hermawan, 2008, Pemasaran New Wave, Gramedia Pustaka Utama). Kedai kopi ini sudah mulai menggunakan media sosial untuk memahami pelanggannya. Mereka tidak perlu menghabiskan anggaran mereka untuk membuat selebaran atau membayar untuk mengiklankan kedai kopi mereka di majalah atau koran lokal.

Perubahan di atas adalah bagian dari proses ReKonsep di mana telah ada beberapa pergeseran dalam konsep Pemasaran Strategis dari Segmentasi, Penargetan dan Posisi Produk yang melibatkan Harga, Produk, Distribusi, dan promosi ke Konsep Pemasaran New Wave. Apa maksudnya? Ini berarti bahwa ada beberapa pergeseran dari Segmentation ke Communitization untuk mencapai tujuan karena sesuai dengan. Selamat datang di Era Pemasaran New Wave di mana ada pergeseran dari STP (Segmentation, Targeting and Positioning) ke Communitization.(Kruseman, Eduard 23 Nov 2010,http://www.slideshare.net/YESFoundation/ trends-in-marketing-and-business-development) Diakses pada 5 Agustus 2016.

Agar berhasil, Click Café harus mengubah paradigma segmentasi pelanggan menjadi komunitisasi, kegiatan promosi menjadi percakapan, dan lebih aktif dalam menciptakan acara komunitas di Click Café yang sering disebut aktivasi komunal. Click Café telah mulai menerapkan pendekatan ini sesuai dengan pengumuman yang telah diposting ke Click Café Facebook Fan Page dan juga anggota Bintaro Photography Community minggu lalu.

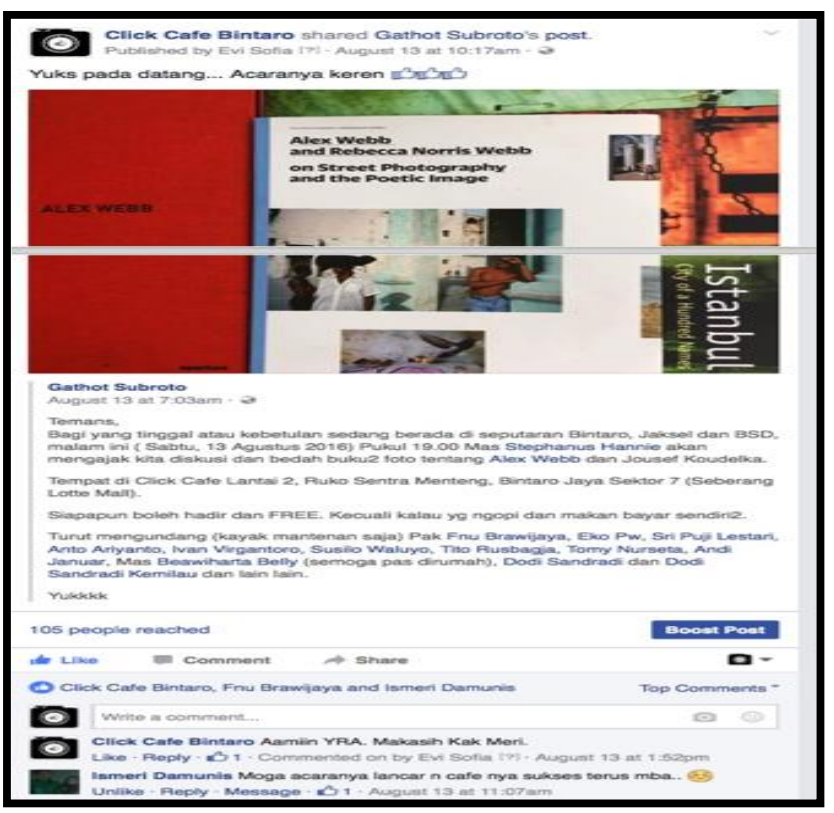

Figure 8. Click Café - Communal Activation

(Monthly Photography Book Club Review Event)

Karena beberapa perubahan yang akan dilakukan di Click Café, akan ada beberapa gerakan dalam penentuan posisi produk Click Café, seperti di bawah ini:

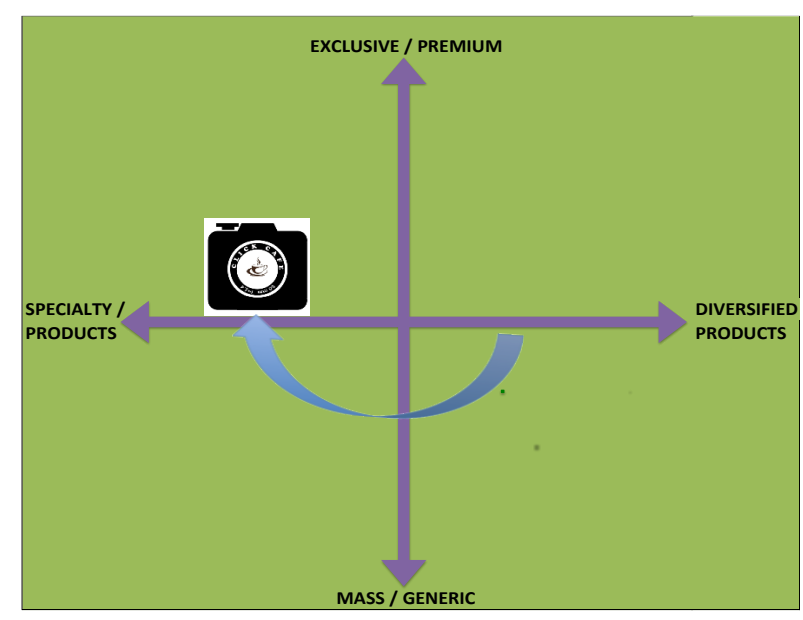

Figure 9. Click Café - New Product Positioning

Click Cafe akan lebih menekankan pada penciptaan kopi "Premium" dengan "Great Barista Skills", mesin kopi berkualitas tinggi yang baru, biji kopi lokal bermutu tinggi khusus dan lebih banyak acara Fotografi dan komunitas lainnya secara berkala dan sesuai jadwal. Peningkatan lainnya adalah rencana Click Café 
untuk menata ulang Coffee Bar yang lebih eksklusif dan tempat memasak khusus. Bar kopi akan berada di lantai pertama untuk menarik orang-orang acak untuk mengunjungi Click Café, dan mengajak komunitas baru lainnya untuk bergabung menjadi pelanggan setia Click Café juga. Juga, tempat memasak di lantai dua untuk memberikan ruang khusus di lantai pertama untuk sangat menghubungkan citra "Exclusive Coffee Bar" dan kedai kopi "Photography Themed" yang hebat.

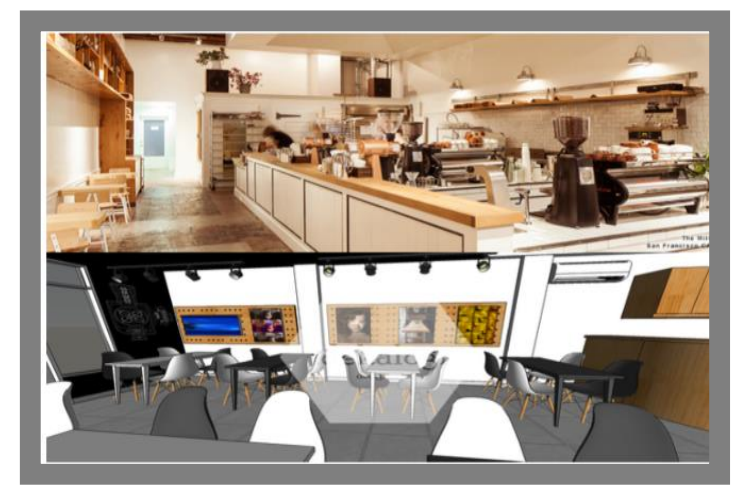

Figure 10. Plan to Re-Layout Click Café's 1st Floor

(Source: The Coffee Bar - La Marzocco California Coffee Shop - http://www.lamarzoccousa.com/)

Karena ada beberapa investasi dalam keterampilan Barista, mesin kopi baru, ubah biji kopi lokal ke tingkat yang lebih tinggi dan kualitas tinggi khusus, maka diperlukan Click Café untuk melakukan strategi harga untuk mengoptimalkan nilai produk dan mencapai yang lain tujuan yang meningkatkan laba. Juga, ada beberapa perbandingan yang telah dilakukan untuk membandingkan harga Click Café dengan kedai kopi lain di sekitar Bintaro. Hasilnya adalah harga kedai kopi ini jauh lebih murah daripada yang lain.

Akan ada beberapa perubahan harga untuk mengoptimalkan keuntungan selama Click Café tetap mempertahankan, meningkatkan kualitas produknya, dan juga meningkatkan layanannya sesuai hasil survei. Pelanggan tidak akan terpengaruh oleh kenaikan harga di Click Café bahkan hingga kenaikan 25\% pada harga saat ini..

\section{KESIMPULAN}

- Kesimpulan dan Rencana Implementasi

Tugas akhir ini selesai untuk memberikan pemahaman dan analisis yang lebih baik tentang apa yang terjadi dengan praktik Click Café saat ini sejak dibuka lebih dari setahun yang lalu. Analisis ini telah mencakup Analisis Faktor Internal (STP dan Bauran Pemasaran) dan Eksternal (PESTEL dan Pesaing - 5 Pasukan Porter) dan metode SWOT mereka untuk memungkinkan kami melihat masalah yang dihadapi Click Café secara komprehensif sehingga dapat mengembangkan strategi pemasaran yang dapat membantu Click Café untuk mencapai tujuan di bawah ini:

Setelah melakukan riset pemasaran secara kuantitatif dan kualitatif, ada beberapa aspek yang harus difokuskan oleh Click Café untuk mempertahankan pertumbuhan bisnisnya:

- Kualitas produk.

- Layanan staf Click Café.

- Sangat membina dan melibatkan masyarakat.

- Memperkuat Proposisi Penjualan Unik mereka sebagai Coffee Shop "Photography Themed" dan "Komunitas".

- Menarik lebih banyak orang secara acak dengan membuat Layout baru di area Click Café.

Dapat disimpulkan bahwa ada pergeseran strategi pemasaran Click Café dari STP (Segmentasi, Penargetan dan Posisi yang meliputi Metode Harga, Tempat, Promosi, dan Distribusi) ke Pemasaran Gelombang Baru 
(Communitization, Conversation, and Communal Activation) untuk merespons keprihatinan di atas. Juga, ada beberapa strategi bisnis alternatif yang kami rekomendasikan yaitu "Re-Layout" dan "Re-Costing". Inilah strategi yang akan menjadikan Click Café bisnis yang sukses di Industri Restoran dan Kedai Kopi.

Ada item tindakan utama sebagai rencana implementasi untuk Click Café agar berhasil dalam industri kedai kopi ini sebagai berikut:

- Strengthening the Unique Point of Sales as "Photography Themed" Coffee Shop and more Exclusive / Premium than before:

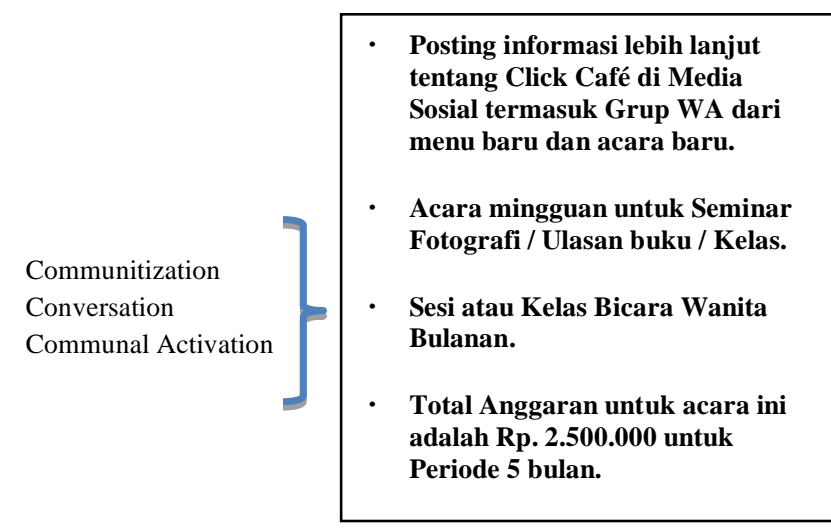

- Meng-upgrade Coffee Bar menjadi lebih Eksklusif / Premium daripada sebelumnya:

Click Café telah menandatangani kontrak dengan Rosso Micro Roastery untuk menyediakan area coffee bar yang ditingkatkan. Mereka berasal dari Konsultasi untuk operasi harian Click Café selama periode 6 Bulan setelah pembukaan baru setelah renovasi dan pelatihan untuk Staf Click Café menjadi Barista, Layanan Kontrol Kualitas selama operasi harian, dan proses pembelian Mesin Kopi.

Di bawah ini adalah total anggaran:

1. Konsultasi untuk operasi harian Click Café \& Pelatihan untuk staf Click Café menjadi Barista Rp. 20.000.000.
2. Layanan Kontrol Kualitas selama Operasi harian Rp. 5.000.000.

3. Mesin Kopi La Marzocco Linea Classic EE termasuk Penggiling, Konsultasi, Pelatihan Kontrol Kualitas Operasi harian. Rp. 115.500.000.

Total Anggaran $\quad$ Rp. 140.500.000.

- Re-Layout

\begin{tabular}{|ll|}
\hline$\circ$ & Renovasi Lantai 1 untuk membuat \\
& Coffee Bar Eksklusif. \\
& Memperbesar lebih banyak ruang di \\
& depan pintu utama untuk area \\
& merokok dengan kipas angin. \\
$\circ$ & Lantai 2 Dapur Area dan Renovasi \\
& Ruang Ibadah. \\
\hline
\end{tabular}

Hingga saat ini, Click Café masih mencari kontraktor untuk menyelesaikan proyek-proyek di atas. Anggaran untuk renovasi ini untuk lantai pertama dan kedua adalah sebesar Rp. 350.000.000.

\section{- Re-Costing}

Sumber daya yang diperlukan untuk fase ini hanyalah data dari total biaya semua pengeluaran, perhitungan ekspektasi laba, dan juga estimasi biaya layanan untuk mendapatkan produk. Ada beberapa item yang harus dipertimbangkan Click Cafe ketika menetapkan harga untuk produk:

1. Mengetahui semua biaya produk untuk mengetahui keuntungan yang kami harapkan.

2. Sesuai survei, para pelanggan Click Café tidak keberatan ketika coffee shop ini menaikkan harganya hingga $25 \%$.

3. Klik Café harus memeriksa secara teratur harga pesaing. Agar berhasil, Click Café harus memberikan nilai lebih kepada 
produk-produknya lebih dari nilainilai pesaing.

4. Harga nomor ganjil membuatnya lebih menarik bagi pelanggan target Click Café. Mereka melihat Rp. 39.500. lebih menarik dari Rp. 40.000 .

(Sumber:http://quickbooks.intuit.c om/r/pricing-strategy/thingsconsider-pricing-your-product/)

Perencanaan Timeline untuk item tindakan di atas adalah sebagai berikut:

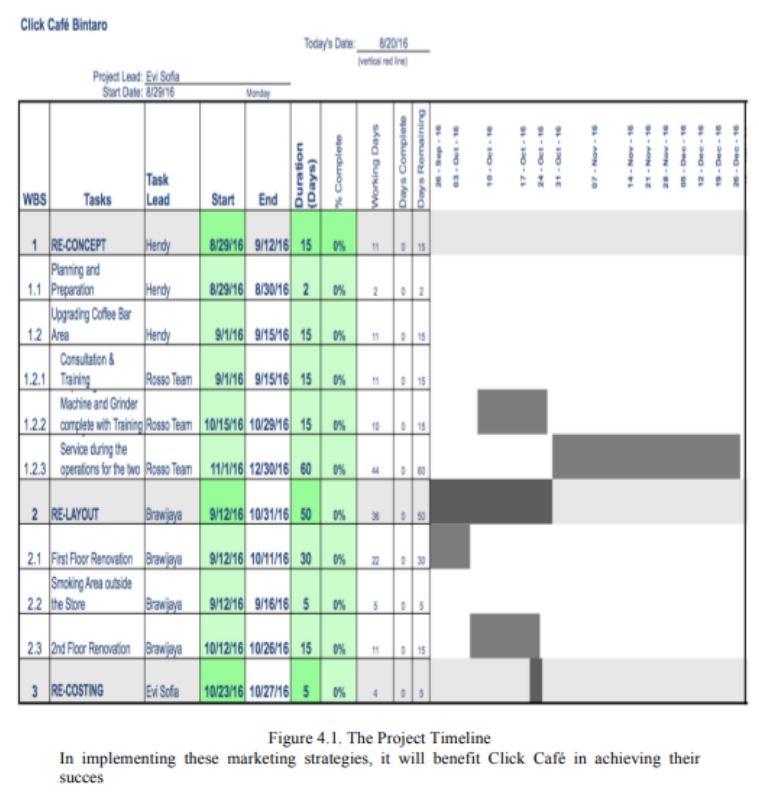

\section{REFERENSI}

Creswell, John W. 2009, Research Design. Sage.

Drucker, Peter 2007. Practice of Management. Harper Business Publisher, New York.

Faustino, Jose M, 1998, Marketing Excellence, p. $51-72$, Phillipine Marketing Association.

Green, E. Paul. 2005, Market Research and Modeling: Progress and Prospects, Springeronline.com.

Isaiah Berlin, 1953. The Hedgehog and the Fox: An Essay on Tolstoy's View of History, London: Weidenfeld \& Nicolson.
Kertajaya, Hermawan, 2008, New Wave Marketing, p. 14-25 Gramedia Pustaka Utama

NK Malhotra on his book "Marketing Research: An Applied approach" in 2007. Porter, E. Michael, January 2008, The Five Competitive Forces that Shape Strategy, Harvard Business Review.

International Coffee Organization (ICO), Statista 2016. United States Department of Agriculture (USDA), 2014, USA in Figures.

http://www.smartinsights.com/digital-marketingstrategy/customer-segmentationtargeting/segmentation-targeting-andpositioning/ (Accessed March 2016)

http://www.marketingdonut.co.uk/marketing/ma rket-research/questionnaires-surveysand-focus-groups/top-20-questions-thatresearch-could-help-you-answer (Accessed June 2016)

http://www.segmentationstudyguide.com/segme ntation-bases/choice-of-segmentationbases/ (Accessed May 2016)

http://www.grin.com/en/e-book/111348/coffeeshop-industry-a-strategic-analysis (Accessed April 2016)

http://www.wikihow.com/Make-a-MarketSurvey (Accessed May 2016)

http://foundersguide.com/how-to-apply-swot-inbusiness/ (Accessed May 2016)

http://www.grin.com/en/e-book/111348/coffeeshop-industry-a-strategic-analysis (Accessed June 2016)

http://smallbusiness.chron.com/swot-analysiscoffee-cafe-15644.html(Accessed June 2016)

http://pestleanalysis.com/difference-swot-peststeep-steeple-analysis/(Accessed June 2016)

http://www.surveysystem.com/sdesign.htm(Acc essed June 2016) 